\title{
Medicinal Chemists Don't Just Make Drugs - The Art of Developing Low Molecular Weight Imaging Agents in Switzerland
}

\author{
Yves P. Auberson*
}

\begin{abstract}
Radiolabeled molecular imaging agents are useful to study drug distribution, target engagement and disease progression in human patients. Medicinal chemists often develop them in parallel to drug discovery programs, to facilitate clinical development or to better understand physiological and pathological processes. While the properties required for imaging agents differ from those of drug candidates, their optimization follows similar principles. Developing them for clinical use also requires a multidisciplinary approach, and is best conducted in a close partnership between pharmaceutical and academic research centers. This article reviews recent scientific advances towards the identification and development of low molecular weight imaging agents in Switzerland.
\end{abstract}

Keywords: Imaging · Radiochemistry $\cdot$ PET $\cdot$ SPECT $\cdot$ Switzerland

\section{Introduction}

The primary objective of medicinal chemists is to design and synthesize biologically active molecules, and optimize them into drug candidates for addressing unmet medical needs. While originally focused on organic synthesis, this discipline has evolved into a highly interdisciplinary research activity. Medicinal chemists interact across the whole spectrum of drug discovery and development: They not only provide drug candidates, but also molecular tools to help biologists explore cellular pathways and identify novel therapeutic targets, as well as diagnostic agents to support clinical trials. This article focuses on research conducted within the Swiss medicinal chemistry community to develop novel molecular imaging agents, both in academia and industry. These new tools facilitate drug development, serve the medical community, and ultimately help bring new drugs to patients more effectively.

${ }^{\star}$ Correspondence: Dr. Y. P. Auberson Novartis Institutes for BioMedical Research WKL-136.6.82

Klybeckstrasse 141

$\mathrm{CH}-4057$ Basel, Switzerland

E-mail: yves.auberson@novartis.com

\section{Molecular Imaging Agents}

Molecular imaging agents for clinical applications come in two flavors: They are either radiolabeled with a positron emitter for detection by positron emission tomography (PET), or with a gamma emitter for single photon emission computed tomography (SPECT). In PET, the positron annihilates an electron in the immediate vicinity of the molecule it originated from, causing the emission of two anti-parallel, $511 \mathrm{keV}$ gamma rays. These are detected by a circular camera placed around the patient, allowing the reconstruction of a three-dimensional image of tracer distribution. In SPECT, the gamma rays emitted by the radioisotope are directly detected by the camera. Both methods provide information on the distribution of the radiolabeled molecule. Depending on the nature of the radiotracer, these data lead to a quantitative understanding of drug distribution, target expression and target engagement, or disease status. The radioisotopes used for small-molecule PET imaging are mostly ${ }^{11} \mathrm{C}\left(\mathrm{t}_{1 / 2}=20 \mathrm{~min}\right)$ and ${ }^{18} \mathrm{~F}\left(\mathrm{t}_{1 / 2}=110 \mathrm{~min}\right)$, and ${ }^{123} I\left(\mathrm{t}_{1 / 2}=13 \mathrm{~h}\right)$ for SPECT.

\subsection{Imaging Pharmacokinetic Properties}

There are three main reasons for using molecular imaging agents. The most obvious is to study the distribution of a drug (or drug candidate) in a patient. While blood samples are easy to collect and provide information about the basic pharmacokinetic properties of a test compound, they do not help to understand its distribution in specific organs. To address this question, the drug itself is radiolabeled and its distribution quantified by imaging. This allows an accurate measurement of concentration over time, for instance in the brain or in tumors that cannot be sampled otherwise.

One such example was published by Briard et al. from the Novartis Institutes for BioMedical Research (NIBR) in Basel, to quantify the penetration of Gilenya (Fig. 1) in the human brain. Gilenya is an oral treatment for multiple sclerosis which modulates the activity of sphingosine 1-phosphate (S1P) receptors. In this case, there was however an additional challenge as the drug itself could not be radiolabeled with a radioisotope of a half-life compatible with its pharmacokinetic properties. To circumvent this issue, the authors had to identify a position where they could introduce an atom of ${ }^{123} \mathrm{I}$, without modifying the pharmacological or pharmacodynamic properties of the parent molecule. Despite a higher molecular weight and significantly increased lipophilicity, the SPECT tracer $\left[^{123} \mathbf{I}\right] \mathbf{B Z M 0 5 5 ^ { [ 1 ] }}$ fulfills these requirements, and allows the quantification over time of the distribution of Gilenya in the human brain. ${ }^{[2]}$

The same principle led to the identification of a pharmacokinetic tracer for siponimod, [ $\left.{ }^{123} \mathbf{I}\right]$ MS565. ${ }^{[3]}$ Siponimod is a second-generation S1P receptor modulator which was originally designed to have a faster brain penetration and wash out than Gilenya. This profile was confirmed with a SPECT imaging study in rhesus ma- 


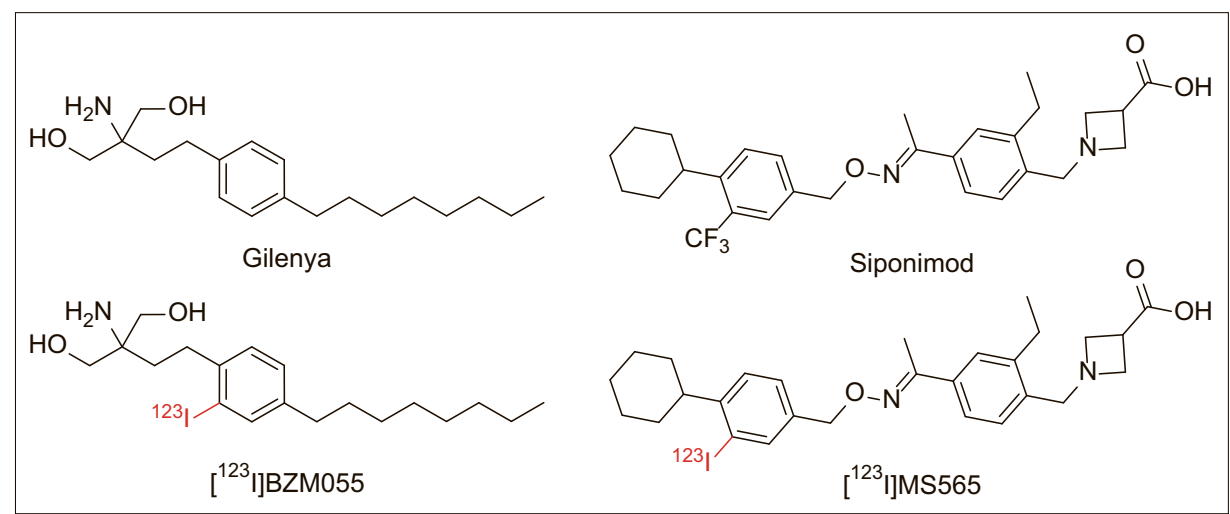

Fig. 1. Structure of Gilenya and siponimod with the corresponding ${ }^{123}$-labeled SPECT tracers, used for quantifying the penetration of the drug into the human brain.

caques $^{[4]}$ (Fig. 2), and while a human study still remains to be conducted, it is expected to deliver similar results.

\subsection{Imaging a Drug Bound to a Target}

A second application of imaging agents is the determination of target engagement (TE), a measure of how much of the therapeutic target is actually occupied by a biologically active molecule. While developing a drug, understanding this parameter is highly valuable as it is the percentage of active molecules really binding to the pharmacological target which matters, in contrast to the amount of drug binding non-specifically to the tissue of interest, or remaining unbound.

Defining the relationship between plasma concentration and actual TE allows precisely determining the dose required for an optimal pharmacodynamic (therapeutic) effect. It helps to improve the design of clinical trials, and supports the demonstration of the efficacy of a drug candidate. In practice, this information will make it possible to avoid testing doses leading to very low target engagement (and therefore unlikely to have any efficacy), as well as doses that are above the dose leading to near-maximal target engagement (likely to increase toxicity without improving therapeutic efficacy)

There are significant differences in the properties of drugs and imaging agents for measuring target engagement (Table 1). Drugs are typically optimized for once-aday oral administration, with a dose aiming at maximal efficacy while limiting the risk of unwanted side-effects. In contrast, imaging agents are administered intravenously as single doses in the microgram range. The low dose proportionally decreases the risk of acute toxicity, which is rarely an issue for imaging agents. Requirements in terms of affinity and selectivity are however much more stringent than for drug candidates: Any labeled molecule that remains unbound, or is bound in a non-specific manner, will appear in the image as noise and affect the quality of the data. The pharmacokinetic properties of imaging agents must also respect strict criteria: since the half-lives of the radioisotopes are short, the time available for image acquisition after synthesis of the radiolabeled molecule is limited. A good candidate must penetrate the tissue of interest quickly, bind, and the unbound fraction must also be eliminated rapidly. In practice, and even though this can be a little longer with ${ }^{123}$ I-labeling, ${ }^{18} \mathrm{~F}$ and ${ }^{11} \mathrm{C}$ imaging agents have very short pharmacokinetic half-lives, of the order of ten minutes or less. Also important is the fact that an imaging agent should not lead to radiometabolites interfering with the signal of the parent molecule. Finally, radiochemical considerations play a role, as the radioisotope is preferably introduced during the very last step of the synthesis.

The principles associated with drug and tracer optimization are similar in many ways, and it is no surprise that medicinal chemists have been using the same approach for both categories. Some differences are however important and must be kept in mind. In particular, while safety and efficacy remain core challenges in drug development, optimizing molecular imaging agents requires more focus on affinity and binding specificity. Many imaging agents have failed because of a lack of specificity for the target of interest. This can be due to additional high-affinity binding targets that were not detected early enough and dialed out in the course of optimization; more frequently however, failure results

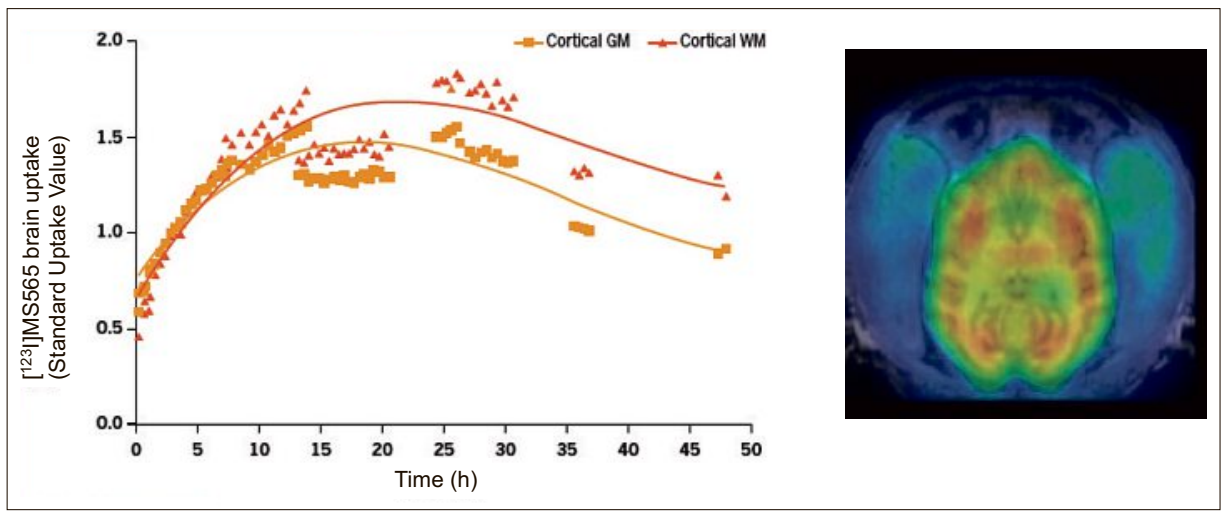

Fig. 2. Left: Decay-corrected time-activity curves displaying an increase of the [123] MS565derived activity concentration in the brain of rhesus macaques until about $20 \mathrm{~h}$ post injection, followed by a faster washout in the grey matter (GM) than in the white matter (WM); $N=2$. Right: fused MR-SPECT transverse brain image in a rhesus macaque (averaged from 7 to $48 \mathrm{~h}$ post-injection).

Table 1. Comparison of desirable properties for low molecular weight drugs and imaging agents.

\section{Properties of a drug}

Long duration of action allowing once-a-day administration

Affinity inducing in vivo efficacy

Specificity desired, not required

Large safety margin after multiple dosing

Active after oral administration

\section{Properties of an imaging agent for target engagement}

Rapid uptake in region of interest, and rapid washout of unbound fraction

High affinity and selectivity, but no efficacy needed

Low non-specific binding, leading to high signal to noise ratio

No acute toxicity with a single dose in the microgram range

Suitable for intravenous administration

No interfering radiometabolites

Structure allows labeling with ${ }^{11} \mathrm{C},{ }^{18} \mathrm{~F}$ or ${ }^{123} \mathrm{I}$ late in synthesis 
from excessive non-specific binding to phospholipids in cell membranes. To help avoid this issue, techniques have been developed to quantify non-specific binding and eliminate weaker candidates early on. Such methodological developments have been recently published by Novartis, which described a HPLC method using the hydrophilic index on immobilized artificial membranes CHI(IAM), to quantify non-specific binding. ${ }^{[5]}$ In parallel, and for the same purpose, F. Hoffmann-La Roche explored the utility of the in vitro lipid membrane binding assay (LIMBA), which is based on the experimental brain tissue and water distribution ratio. ${ }^{[6]}$ Both methods have merit and are useful predictive tools.

There are several recent examples of novel target engagement tracers. In particular, the work of Ametamey et al. (ETH Zurich) on tracers for the metabotropic glutamate receptor type 5 (mGluR5) deserves being mentioned. Drug candidates acting on mGlu5 receptors are or have been evaluated for several therapeutic applications including depression, ${ }^{[7]}$ Fragile $\mathrm{X}$ syndrome ${ }^{[8]}$ and L-DOPA induced dyskinesia in Parkinson's disease patients. ${ }^{[9]}$ Initially, a collaboration with Novartis led to the identification of $\left[{ }^{11} \mathbf{C}\right] \mathbf{A B P} \mathbf{B 8 8}{ }^{[10,11]}$ (Fig. 3), a very efficient tracer that could successfully be applied in the clinic, as discussed below. The distribution of $\mathrm{mG}$ lu5 receptors in the human brain is readily measurable with this tracer, as illustrated in Fig. 4.

The half-life of ${ }^{11} \mathrm{C}$ is, however, very short (20 $\mathrm{min}$ ), and using this isotope is associated with operational challenges, limiting potential for tracer distribution. Further work by the group at the ETHZ led after much perseverance, to the identification of a longer-lived derivative, $\left[{ }^{18} \mathbf{F}\right]$ PSS232, ${ }^{[12]}$ which appears very promising and complements the tool kit for mGluR5 imaging. The excellent specificity of this tracer, confirmed by its distribution in the

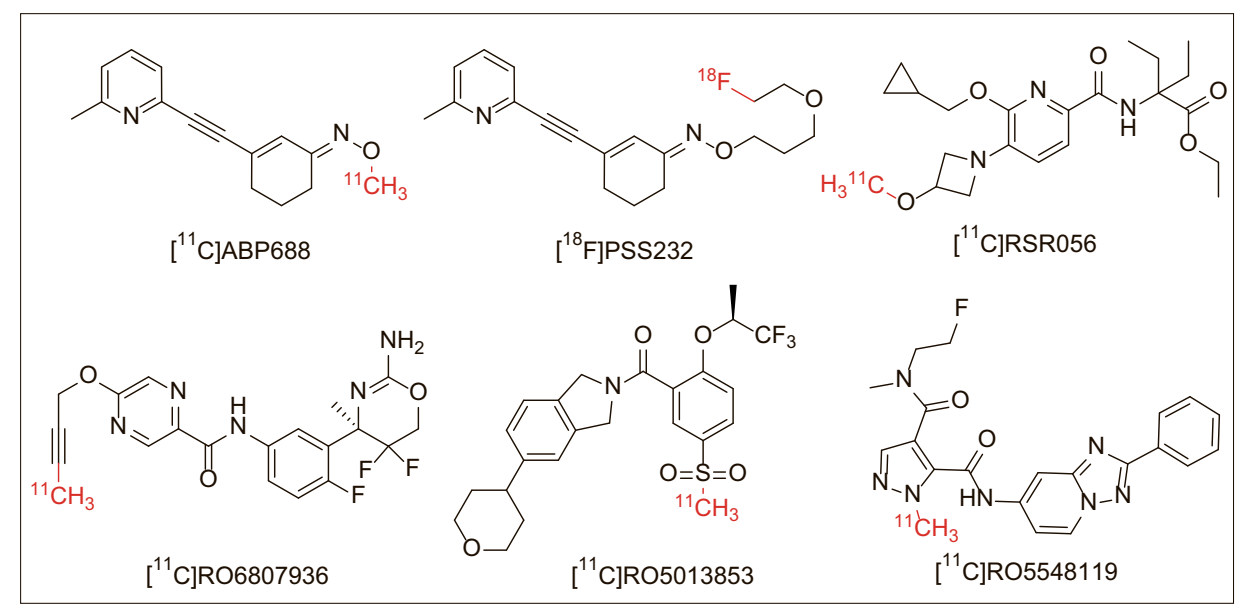

Fig. 3. Structure of novel PET tracers for imaging target engagement in the brain.

rat brain in wild-type compared to mGluR5 knock-out animals, or after blocking with another mGlu5 antagonist, is illustrated in Fig. 4.

The group from the ETHZ also worked with F. Hoffmann-La Roche in Basel for the development of a PET tracer to measure target engagement of the cannabinoid type 2 (CB2) receptor. Mostly expressed on immune cells, CB2 receptors are thought to play an important role in diseases with an inflammatory component, including Parkinson's and Alzheimer's disease, ${ }^{[13]}$ as well as multiple sclerosis ${ }^{[14]}$ and ALS. ${ }^{[15]}$ Even though a number of CB2 receptor PET ligand candidates has been reported in the literature, they suffer from suboptimal properties. This collaboration led to the identification of $\left.{ }^{[1} \mathbf{C}\right] \mathbf{R S R 0 5 6}$, a new pyridine-based PET tracer candidate, which was evaluated in a model of lipopolysaccharide- (LPS-) induced neuroinflammation in mice. ${ }^{[16]}$ A markedly higher signal in the brain of LPS-treated versus control mice indicates that this compound might have the potential to image inflammation in the human brain.

The imaging tracer development group at F. Hoffmann-La Roche also disclosed the results of several other projects, including a tracer candidate for the $\beta$-secretase enzyme (BACE), [ $\left.{ }^{11} \mathrm{C}\right] \mathbf{R O 6 8 0 7 9 3 6} .{ }^{[17,18]}$ This tracer represents a valuable tool for in vitro work, although in vivo its brain uptake in non-human primates was found to be moderate, making the use of this tracer difficult.

A target of interest for the treatment of psychiatric diseases is the glycine transporter type 1 (GlyT1). F. Hoffmann-La Roche has discovered and developed bitopertin, a GlyT1 inhibitor which was initially evaluated for the treatment of negative symptoms of schizophrenia, and later for obsessive-compulsive disorder. A PET tracer, $\left[{ }^{11} \mathbf{C}\right] \mathbf{R O 5 0 1 3 8 5 3},{ }^{[19]}$ was developed in parallel to bitopertin, to facilitate its development. Receptor occupancy studies were performed in baboons ${ }^{[20]}$ and healthy human volunteers. ${ }^{[21,22]}$ They allowed the engagement of GlyT1 to be quantified after oral administration of the drug, successfully defining the relationship between its plasma concentration and brain receptor occupancy. Besides helping the selection of a clinical dose, such data helps with the interpretation of clinical results, whether positive or negative, by confirming the
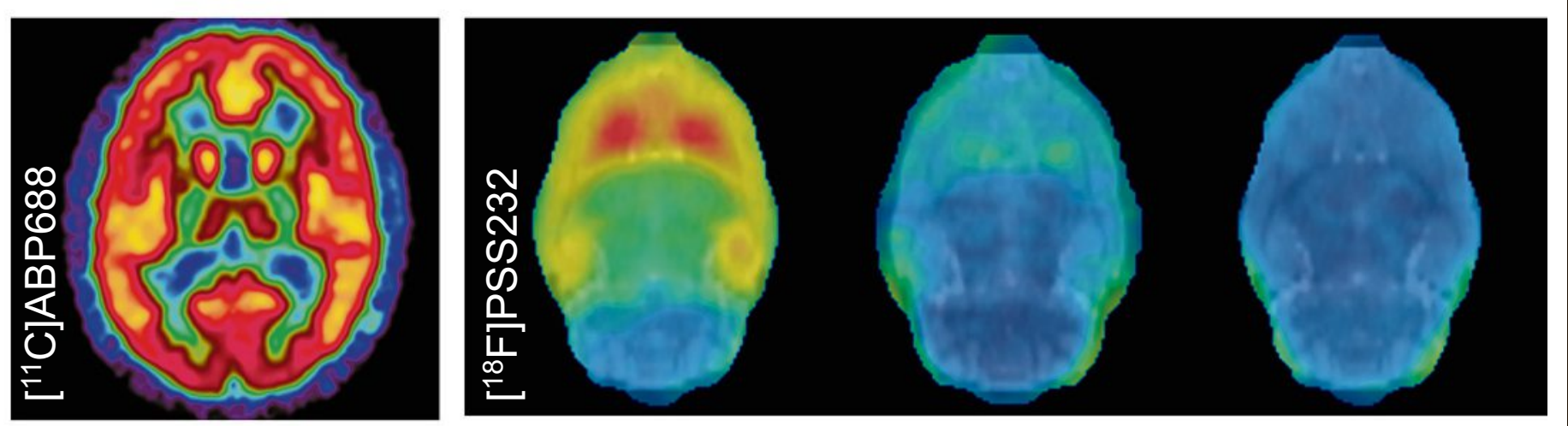

Fig. 4. Left panel: Distribution of mGlu5 in a healthy volunteer, imaged with [11 C]ABP688. Right panel: Distribution of mGlu5 in the rat brain, imaged with [ $\left.{ }^{18} \mathrm{~F}\right]$ PSS232. Left: wild type, baseline; center: wild type after blocking with $1 \mathrm{mg} / \mathrm{kg}$ i.v. of mGluR5 antagonist MMPEP; right: mGluR5 knockout, baseline. PET images were averaged from 2 to 60 min post [ $\left.{ }^{18} \mathrm{~F}\right] \mathrm{PSS} 232$ injection. Blue: low signal; red: high signal. Images courtesy of Prof. Simon Ametamey, ETHZ. 
extent of target engagement under actual clinical testing conditions.

Finally, F. Hoffmann-La Roche also disclosed a tracer for phosphodiesterase 10A (PDE10A), which was identified using HPLC-MS/MS. ${ }^{[23]}$ Recent technological improvements have made it possible to develop exquisitely sensitive bioanalytical methods using this technique. Indeed, the sensitivity of HPLC-MS/MS now rivals what can be achieved with a tritiated ligand. Once implemented, it also has a much higher throughput than could be achieved with the tritiation of successive candidates. In this program, a LC-MS/ MS protocol was used to efficiently profile thirty-eight unlabeled high affinity PDE10A inhibitors. Their concentration in the striatum was compared to their concentration in the cerebellum, with the latter being used as a reference region devoid of receptor. The best candidate identified by LC-MS/MS was radiolabeled with ${ }^{11} \mathrm{C}$, and the PET tracer $\left[{ }^{11} \mathbf{C}\right] \mathbf{R O 5 5 4 8 1 1 9}$ applied for visualization and quantification of PDE10A in non-human primates (Fig. 5). [24] These results confirmed its potential as a tracer for target engagement studies in human subjects.

\subsection{Imaging the Disease}

Molecular imaging agents can also provide information on disease status and pro- rapidly and with few patients than when using more traditional (and sometimes rather imprecise) clinical evaluation methods, such as qualitative questionnaires or quality-of-life assessments.

As mentioned earlier, a well-studied example is [ $\left.{ }^{11} \mathbf{C}\right] \mathbf{A B P 6 8 8}$. It was first used to look at mGluR5 levels in patients suffering from major depression, ${ }^{[25]}$ and revealed decreased receptor levels in several brain areas. These changes were confirmed by Western blot quantification of mGluR5 expression in the post-mortem brain samples of depressed patients, as compared to age-matched non-depressed subjects. While this finding might not apply to all age groups, ${ }^{[26]}$ mGluR5 modulation thus seems to play a role in depression. Further studies with $\left[{ }^{11} \mathbf{C}\right] \mathbf{A B P} \mathbf{8 8 8}$ were conducted in obsessive-compulsive disorder patients, ${ }^{[27]}$ after sleep deprivation ${ }^{[28]}$ and in tobacco addiction ${ }^{[29]}$ to quantify changes in mGluR5 expression. It is interesting to note that sleep deprivation is a rapid-acting, well-established method to treat acute depression episodes, ${ }^{[30]}$ and that it led to an increase in mGlu5 receptor expression. This information, combined with the results of the depression imaging study, suggests that pharmacologically increasing mGluR5 activity might be helpful in treating some aspects of major depression. Such examples, while not proving defini- tive causal relationships between the level of receptor expression and the condition of the subject, illustrate the use of imaging tracers in testing new hypotheses, and open a window toward a better understanding of the role of their target in human pathologies.

Tumor imaging is an application where PET and SPECT imaging tracers have made a strong impact, facilitating the early identification of primary tumors and metastases. This is an area dominated by well-established tracers based on the detection of increased tumor metabolism, ${ }^{[31]}$ and specific peptide- or antibody-based imaging agents. ${ }^{[32]}$ For instance, arginine-glycine-aspartic acid (RGD)containing peptides are well-established PET probes to image angiogenesis and tumor growth. ${ }^{[33]}$ They come with the limitations usually associated with peptides in their use as imaging agents, including a permeation that varies in different tumors, and the need to use a linker and radiometal for labeling. At the Hôpital Universitaire de Genève, Seimbille et al. looked at a novel series of non-peptidic antagonists of the $\alpha 5 \beta 1$ integrin receptor. ${ }^{[34]}$ They developed a method for the efficient radiolabeling of a PET tracer candidate for this target, $\left[{ }^{18}\right.$ F]FPMt ${ }^{[35]}$ based on click chemistry (Fig. 6).

Another area of intense research ac-

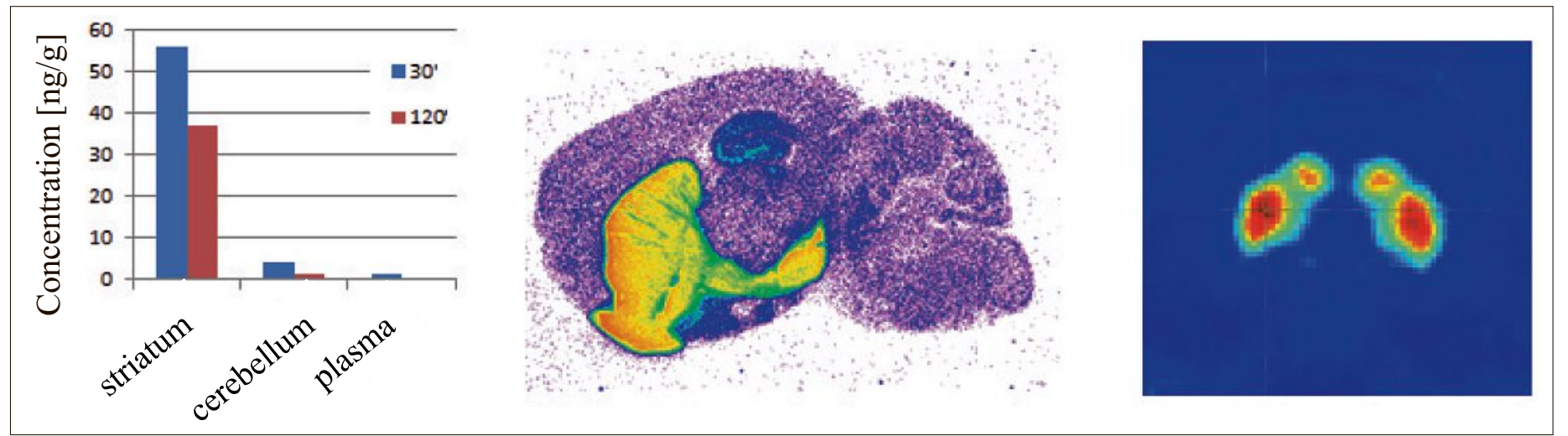

Fig. 5. Left: Target-mediated differential distribution in rat brain regions after i.v. administration of a microdose (10 $\mu \mathrm{g} / \mathrm{kg})$ of cold RO5548119, as measured with HPLC-MS/MS. Center: Rat brain autoradiography with $\left.{ }^{3} \mathrm{H}\right] \mathrm{RO5548119}$, showing accumulation in the striatum, and to a lower extent in the hippocampus, but not in the cerebellum. Right: PET image of a monkey brain obtained with $\left[{ }^{18} \mathrm{~F}\right] \mathrm{RO} 5548119$, also showing a strong signal in the striatum. Images courtesy of Dr. Luca Gobbi, F. Hoffman-La Roche.

gression. Such agents are sometimes those used for imaging a drug target, provided the expression of the target is directly correlated to disease severity. In other cases, they are designed to directly image disease markers such as inflammation, hypoxia or protein deposition. By quantifying the marker, and hence the disease, they help clinicians evaluate the therapeutic efficacy of a drug more precisely. They also help select the right patient population for a study. These results can be achieved more

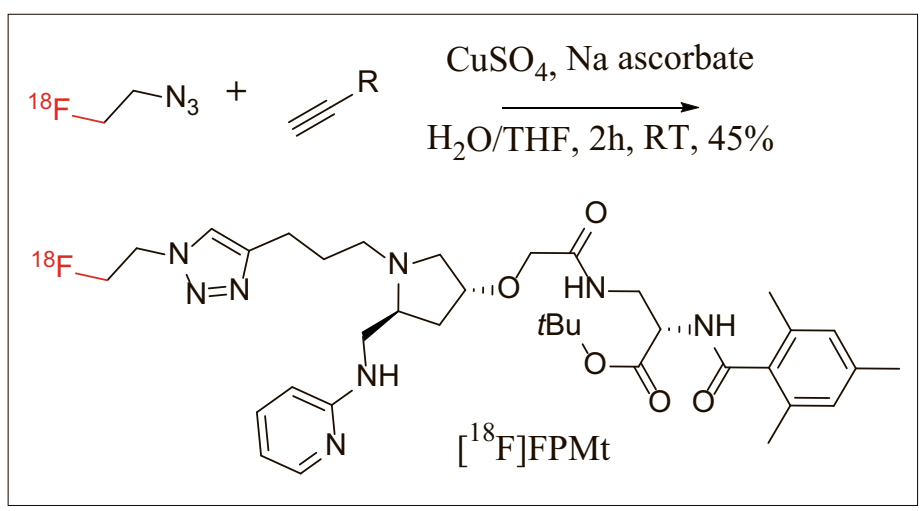

Fig. 6. The

${ }^{18} \mathrm{~F}$-radiolabeling of $\left[{ }^{18}\right.$ F]FPMt, an $\alpha 5 \beta 1$ integrin receptor non-peptidic ligand, using click chemistry. 
tivity aims at improving the diagnosis of neurodegenerative diseases. For instance, it is well-known that both amyloid plaques and neurofibrillary tangles (NFT) are associated with Alzheimer's disease. There are approved tracers available for the quantification of amyloid deposits, ${ }^{[36]}$ however these do not correlate well with the progression of the disease. NFT are composed of hyperphosphorylated Tau protein, and their density in the brain is considered more directly associated with neurodegeneration and cognitive impairment than the amyloid load. They have the potential to improve clinical practice for the early detection and staging of Alzheimer's disease, and accelerate the clinical development of disease modifying therapies. There are several tracers under evaluation for imaging Tau, ${ }^{[37]}$ but none has yet been approved by the health authorities and made broadly available.

F. Hoffmann-La Roche recently discussed $\left[{ }^{18} \mathbf{F}\right] \mathbf{R O}$-6958948, ${ }^{[38]}$ an imaging tracer for NFT. This compound originates from a series of high-affinity binders, with marked selectivity for binding to Tau aggregates compared to amyloid deposits. The chemical structure of this tracer is not yet disclosed, but a preliminary evaluation of its imaging performance in the human brain ${ }^{[39]}$ appears promising. The signal observed is consistent with the published NFT distribution in Alzheimer's disease patients, with no brain-penetrant metabolites and very little retention in areas expected to be devoid of the target.

\subsection{New Methods for Tracer Synthesis}

The availability of novel methods for labeling tracer candidates remains a limitation for medicinal chemistry, especially with regard to the introduction of ${ }^{18} \mathrm{~F}$. Despite marked progress over the last five years, ${ }^{[40]}$ synthetic limitations remain severe, making prosthetic groups a useful option for introducing radiolabels on larger chemical entities such as peptides or antibodies. One recent publication by Seimbille et al. describes the development of a novel 2-cyanobenzothiazole-based prosthetic group, $\left[{ }^{18}\right.$ F]FPyPEGCBT. ${ }^{[41]}$ The use of this reagent was exemplified by coupling with a cyclo-(RDGfK) analogue (Fig. 7). Its efficient preparation, coupled to a good reactivity with terminal cysteine residues, makes it a promising agent for the ${ }^{18}$ F-labeling of peptides.

The group of R. Schibli and S. Ametamey at the Paul-Scherrer Institute and ETHZ performed an interesting study, exploring the effect of the regiochemistry of folic acid conjugation on affinity and organ distribution. ${ }^{[42,43]}$ They found that the affinity for folate receptors (FR) did not differ between $\alpha$ - and $\gamma$-conjugates (Fig.

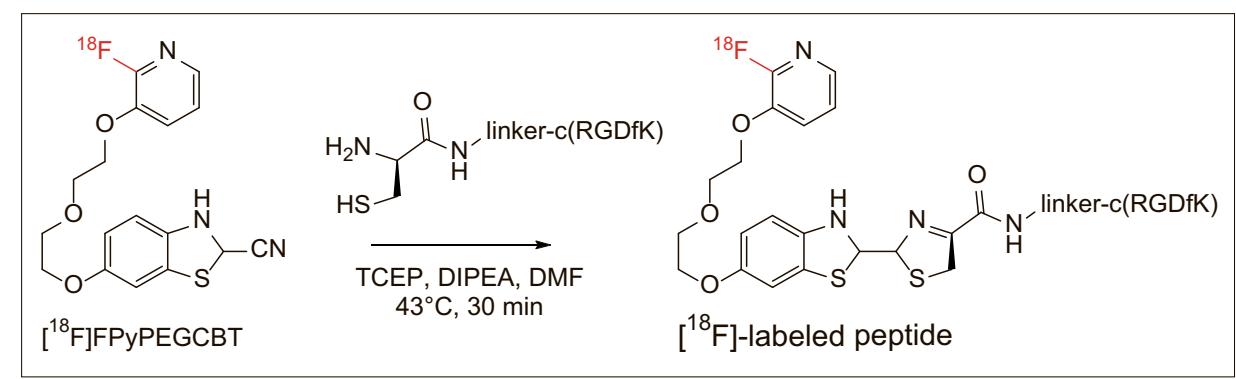

Fig. 7. Conjugation of the $\left[{ }^{18} \mathrm{~F}\right]$ FPyPEGCBT prosthetic group to an 1,2-aminothiol-containing linker with a c(RGDfK) payload.
8). In vivo PET imaging studies in mice bearing folate receptor-expressing tumors showed that both regioisomers were enriched in tumors to a similar extent, and that the signal could be blocked by injection of folic acid, confirming its specificity (Fig. 9). In contrast, they observed that liver and kidney radioactivity uptake was significantly influenced by the substitution pattern. For the examples illustrated in Fig. 8 , the ratio of tumor to liver exposure for the $\alpha$ - and $\gamma$-conjugates was respectively 4.5 and 0.84 . In this example, $\alpha$-conjugation is therefore about five times better at targeting radioactivity to tumor tissue. These findings are important for the design of future folate-directed imaging agents, radiotherapeutics, and possibly drug delivery constructs based on this principle.
Not mentioned in this article is the work done by these research groups, and others, to develop imaging tracers based on peptides and larger molecules. The remit of medicinal chemistry is constantly expanding and accordingly, an increasing range of molecule classes are explored as potential imaging agents. It includes novel low-molecular weight compound classes, but also biologicals, from small peptides to antibody-drug conjugates. This area is beyond the scope of this article, and would deserve a separate discussion.

\section{Conclusion}

Low-molecular weight imaging tracer development in Switzerland takes place in

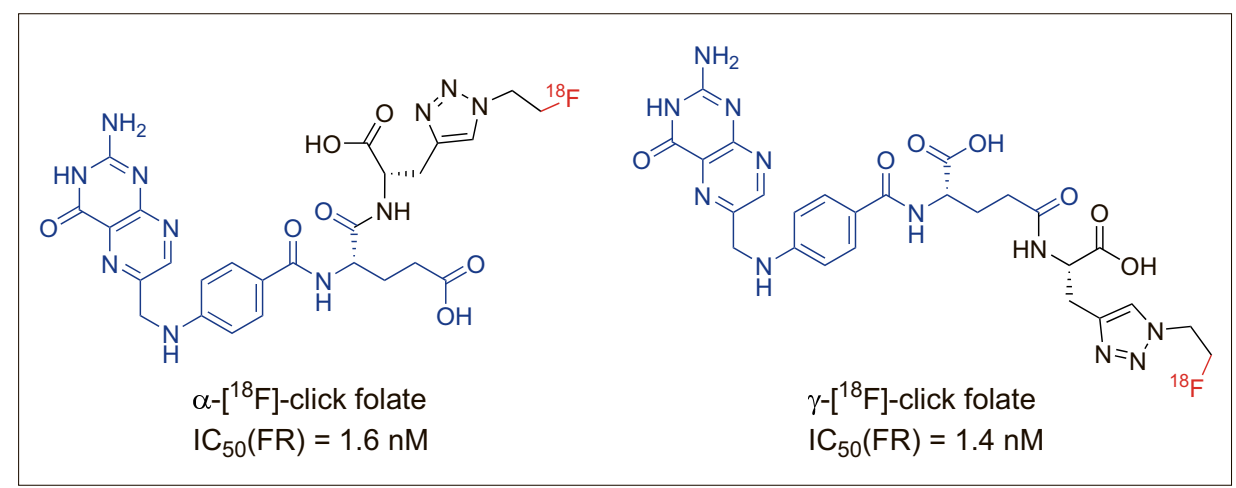

Fig. 8. $\alpha$ - and $\gamma-\left[{ }^{18} \mathrm{~F}\right]$-fluoroethyl folate conjugates and their affinity for the folate receptor.

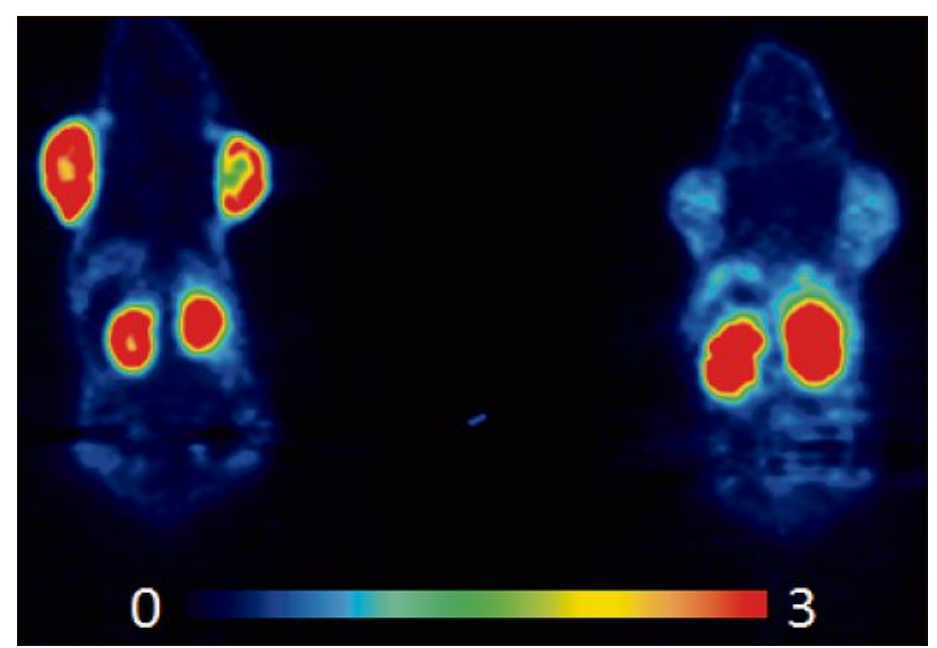

Fig. 9. Imaging of folate receptor-positive tumor in rat using a $\left[{ }^{18} \mathrm{~F}\right]$ fluorodeoxyglucose-folate conjugate. Coronal PET images averaged from 75-150 min post radiotracer injection. For the blocking experiment the animal received i.v. injection of $100 \mu \mathrm{g}$ folic acid 10 min before injection of the folate radiotracer. Image courtesy of Prof. Simon Ametamey, ETHZ. 
a limited number of specialized research groups. Multidisciplinary in essence, this community interacts actively across the traditional borders of industry and academic research. The discovery of novel PET and SPECT imaging agents provides valuable molecular tools for the exploration of biochemical processes and diseases. By enhancing our understanding of how drugs work, and of the pathologies they aim to treat, imaging tracers facilitate the selection of the best clinical candidates and accelerate their development. Their discovery and advancement to clinical use require high-quality science, and time, underscoring the need to consider tracer development during the early phase of drug discovery project, especially when such tools can address clinical questions that cannot be answered otherwise. The fact that pharmaceutical companies, academic research groups and hospital imaging centers all contribute to this effort demonstrates their interest for new molecular imaging tools, and the potential of imaging to ultimately benefit patients.

\section{Acknowledgement}

The author sincerely thanks Dr. Simon M. Ametamey and Dr. Luca Gobbi for valuable comments and discussions, and for sharing illustration material.

Received: March 15, 2016

[1] E. Briard, D. Orain, C. Beerli, A. Billich, M. Streiff, M. Bigaud, Y. P. Auberson, ChemMedChem 2011, 6, 667.

[2] G. Tamagnan, A. Tavares, O. Barret, D. Alagille, J. Seibyl, K. Marek, P. R. Maguire, E. Briard, R. Schmouder, R. Behrje, D. Jennings, Multiple Sclerosis 2012, 18, 379.

[3] E. Briard, B. Rudolph, S. Desrayaud, J. A Krauser, Y. P. Auberson, ChemMedChem 2015 , 10, 1008.

[4] O. Barret, A. Tavares, D. Alagille, T. Morley, C Papin, R. P. Maguire, E. Briard, Y. P. Auberson, G. Tamagnan, American Academy of Neurology 66 $6^{\text {th }}$ Annual Meeting, 2014, Apr. 26 - May 3 Philadelphia, Abst. 2510.

[5] Z. Jiang, J. Reilly, B. Everatt, E. Briard, $J$ Pharm. Biomed. Anal. 2011, 54, 722 .

[6] F. Assmus, A. Seelig, L. Gobbi, E. Borroni, P. Glaentzlin, H. Fischer, Eur. J. Pharm. Sci. 2015 $79,27$.

[7] K. Fuxe, D. O. Borroto-Escuela, Expert Opin. Investig. Drugs 2015, 24, 1247.

[8] B. Gomez-Mancilla, E. Berry-Kravis, R. Hagerman, F. von Raison, G. Apostol, M. Ufer,
F. Gasparini, S. Jacquemont, Expert Opin. Investig. Drugs 2014, 23, 125.

[9] C. Finlay, S. Duty, J. Neural Transm. 2014, 121, 861.

[10] S. A. Ametamey, M. Simon, L. J. Kessler, M. Honer, M. T. Wyss, A. Buck, Alfred, S. Hintermann, Y. P. Auberson, F. Gasparini, P. A. Schubiger, J. Med. Chem. 2006, 47, 698

[11] S. M. Ametamey, V. Treyer, J. Streffer, M. T. Wyss, M. Schmidt, M. Blagoev, S. Hintermann, Y.P. Auberson, F. Gasparini, U.C. Fischer, A. Buck, J. Nucl. Med. 2007, 48, 247.

[12] S. M. Sephton, L. Mu, M. Dragic, S. D. Kramer, R. Schibli, S. M. Ametamey, Synthesis 2013, 45, 1877.

[13] S. G. Fagan, V. A. Campbell, Br. J. Pharmacol. 2014, 171, 1347.

[14] A. J. Sanchez Lopez, L. Roman-Vega, E. Ramil Tojeiro, A. Giuffrida, A. Garcia-Merino, Clin. Exp. Immunol. 2015, 179, 119.

[15] L. G. Bilsland, L. Greensmith, Curr. Pharm. Des. 2008, 14, 2306.

[16] R. Slavik, U. Grether, A. Muller Herde, L. Gobbi, J. Fingerle, C. Ullmer, S. D. Kramer, R. Schibli, L. Mu, S. M. Ametamey, J. Med. Chem. 2015, 58, 4266 .

[17] E. Borroni, L. Gobbi, H. Hilpert, M. Honer, D. Muri, R. Narquizian, A. Polara, WO Patent Appl. No. WO2012168175A1, 2012.

[18] L. Gobbi, M. Honer, H. Hilpert, A. Polara, D. Muri, J. Helmut, D. P. Holt, H. T. Ravert, R. F. Dannals, H. Valentine, H. Kuwabara, D. F. Wong, E. Borroni, J. Label Compd Radiopharm. 2013, 56, S299.

[19] E. Pinard, S. Burner, P. Cueni, T. Hartung, R. D. Norcross, P. Schmid, P. Waldmeier, G. Zielinski, H. T. Ravert, D. P. Holt, R. F. Dannals, J. Label. Compd Radiopharm. 2011, 54, 702.

[20] E. Borroni, Y. Zhou, S. Ostrowitzki, D. Alberati, A. Kumar, D. Hainzl, T. Hartung, J. Hilton, R. F. Dannals, D. F. Wong, NeuroImage 2013, 75, 291.

[21] D. F. Wong, S. Ostrowitzki, Y. Zhou, V. Raymont, C. Hofmann, E. Borroni, A. Kumar, N. Parkar, J. R. Brasic, J. Hilton, R. F. Dannals, M. Martin-Facklam, NeuroImage 2013, 75, 282.

[22] M. Martin-Facklam, F. Pizzagalli, Y. Zhou, S Ostrowitzki, V. Raymont, J. R. Brasic, N. Parkar, D. Umbricht, R. F. Dannals, R. Goldwater, D. F. Wong, Neuropsychopharmacol. 2013, 38, 504.

[23] E. Chernet, L. J. Martin, D. Li, A.B. Need, V. N. Barth, K. S. Rash, L. A. Phebus. Life Sciences 2005, 78,340

[24] L. Gobbi, M. Honer, R. Alvarez Sanchez, C. Flament, A. Flohr, H. Schaffhauser, D. Muri, T. Hartung, E. Borroni, Chimia 2015, 69, Suppl. 7-8, MC-013.

[25] A. Deschwanden, B. Karolewicz, A. M. Feyissa, V. Treyer, S. M. Ametamey, A. Johayem, C. Burger, Y. P. Auberson, J. Sovago, C. A. Stockmeier, A. Buck, G. Hasler, Am. J. Psych. 2011, 168,727 .

[26] C. DeLorenzo, J. Sovago, J. Gardus, J. Xu, J. Yang, R. Behrje, J. S. D. Kumar, D. P. Devanand, G. H. Pelton, C. A. Mathis, N. S.
Mason, B. Gomez-Mancilla, H. Aizenstein, J. J. Mann, R. V. Parsey, Transl. Psychiatry 2015, 5 , 693.

[27] F. Akkus, S. Terbeck, S. M. Ametamey, M. Rufer, V. Treyer, C. Burger, A. Johayem, B. Gomez Mancilla, J. Sovago, A. Buck, G. Hasler, Int. J. Neuropsychopharmacol. 2014, 17, 1915.

[28] K. Hefti, S. C. Holst, J. Sovago, V. Bachmann, A. Buck, S. M. Ametamey, M. Scheidegger, T. Berthold, B. Gomez-Mancilla, E. Seifritz, Erich, H. P. Landolt, Bio. Psychiatry 2013, 73, 161.

[29] F. Akkus, S. M. Ametamey, V. Treyer, C. Burger, A. Johayem, D. Umbricht, B. Gomez Mancilla, J. Sovago, A. Buck, G. Hasler, Proc. Natl. Acad. Sci. USA 2013, 110, 737.

[30] U.-M. Hemmeter, J. Julia Hemmeter-Spernal, J.-C. Krieg, Expert Rev. Neurother. 2010, 10, 1101.

[31] D. Y. Lewis, D. Soloviev, K. M. Brindle, $C A$ : Cancer J. Clin. 2015, 21, 129.

[32] L. E. Lamberts, S. P. Williams, A. G. T. Terwisscha van Scheltinga, M. N. Lub-de Hooge, C. P. Schröder, J. A. Gietema, A. H. Brouwers E. G. E. de Vries, J. Clin. Oncol. 2015, 33, 1491.

[33] P. A. Knetsch, C. Zhai, C. Rangger, M. Blatzer, H. Haas, P. Kaeopookum, R. Haubner, C. Decristoforo, Nucl. Med. Biol. 2015, 42, 115.

[34] R. Stragies, F. Osterkamp, G. Zischinsky, D Vossmeyer, H. Kalkhof, U. Reimer, G. Zahn, $J$. Med. Chem. 2007, 50, 3786.

[35] A. Monaco, O. Michelin, J. Prior, C. Rueegg, L. Scapozza, Y. Seimbille, J. Label. Comp. Radiopharm. 2014, 57, 365.

[36] S. M. Landau, B. A. Thomas, L. Thurfjell, M. Schmidt, R. Margolin, M. Mintun, M Pontecorvo, S. L. Baker, W. J. Jagust, the Alzheimer's Disease Neuroimaging Initiative, Eur. J. Nucl. Med. Mol. Imaging 2014, 41, 1398.

[37] M. Ariza, H. C. Kolb, D. Moechars, F. Rombouts, J. I. Andrés, J. Med. Chem. 2015, 58,4365 .

[38] M. Honer, H. Knust, L. Gobbi, M. Koerner, D. Muri, R. Comley, E. Borroni, 10th Hum. Amyloid Imaging Conf. 2016, Jan 13-15, Miami, Abst. PE42.

[39] D. Wong, R. Comley, H. Kuwabara, N. George, P. Rosenberg, C. Lyketsos, M. Thambisetty, H. Knust, M. Honer, F. Boess, S. Ostrowitzki, R. Dannals, E. Borroni, 10th Hum. Amyloid Imaging Conf. 2016, Jan 13-15, Miami, Abst. S1-PP57.

[40] S. Preshlock, M. Tredwell, V Gouverneur, Chem. Rev. 2016, 116, 719

[41] J. A. H. Inkster, D. J. Colin, Y. Seimbille, Org. Biomol. Chem. 2015, 13, 3667.

[42] S. D. Boss, T. Betzel, C. Muller, C. R. Fischer, S. Haller, J. Reber, V. Groehn, R. Schibli, S. M. Ametamey, Bioconjugate Chem. 2016, $27,74$.

[43] A. Muller, K. Beck, Z. Rancic, C. Muller, C. R. Fischer, T. Betzel, P. A. Kaufmann, R. Schibli, S. D. Kraemer, S. M. Ametamey, Mol. Imaging 2014, 13,1 . 